\title{
Onde a reforma ainda não chegou: ecos da assistência às urgências psiquiátricas
}

I 1 Andiara Araújo Cunegundes de Brito, 2 Diego Bonfada,

3 Jacileide Guimarães I

Resumo: No âmbito da Reforma Psiquiátrica brasileira, a assistência às crises psíquicas representa um desafio para as políticas de saúde, em especial para os serviços de urgências. Este artigo tem como objetivo discutir o atendimento prestado às crises psiquiátricas pelos profissionais de saúde do Serviço de Atendimento Móvel de Urgência (Samu). A pesquisa é resultante de uma dissertação de mestrado em Enfermagem, realizada em Natal, e que utilizou a entrevista semiestruturada e a observação direta como instrumentos de coleta de informações. Os dados obtidos foram submetidos à técnica da análise temática, aplicada em estudos qualitativos. Com esse referencial, surgiram quatro categorias de análise: a polícia militar e as ocorrências psiquiátricas; características do atendimento prestado pelo Samu em urgências psiquiátricas; necessidade de capacitação profissional; responsabilidade do Samu com as urgências psiquiátricas. A discussão aponta que elementos associados à prática manicomial, como o uso da força coercitiva, exercida sobretudo pelo auxílio de policiais militares, ainda sustentam o ideário e a assistência prestada pelos profissionais entrevistados. Todavia, a assistência prestada nesses casos precisa manter os laços sociais, ambientais e afetivos dos sujeitos, evitando medidas violentas, de cunho repressor ou excludente. Portanto, a pesquisa suscitou reflexão sobre questôes relevantes para o processo de concretização da Reforma Psiquiátrica brasileira no espaço do atendimento pré-hospitalar de urgência.

Palavras-chave: saúde mental; emergências; intervenção na crise.

1 Programa de Pós-Graduação em Saude Coletiva, niversidade Federal do Rio Grande do Norte. Natal-RN Brasil. Endereço eletrônico: andiara_acm@hotmail.com

2 Programa de Pós-Graduação em Saúde Coletiva, Universidade Federal do Rio Grande do Norte. Natal-RN, Brasil. Endereço eletrônico: diegobonfada@hotmail.com

${ }^{3}$ Programa de Pós-Graduação em Saúde Coletiva Universidade Federal do Rio Brasil. Endereço eletrônico: jaciguim@yahoo.com.br 


\section{Introdução}

Antes escondida e isolada nos manicômios, agora como evento de saúde mental, a crise psíquica ganhou mais visibilidade na sociedade após o movimento de desinstitucionalização fundamentado pela Reforma Psiquiátrica brasileira. A crise ou intensificação do sofrimento mental dos pacientes chega à comunidade, que se torna espaço para sua manifestação por meio da busca pela diminuição das internações hospitalares e valorização do tratamento comunitário.

Para a sociedade, familiares e muitos profissionais de saúde, a crise psíquica, na maioria dos casos, é vista como uma demanda urgente quando começa a afetar a rotina interpessoal. $\mathrm{Na}$ maior parte das ocorrências, as pessoas, sentindo-se incomodadas pelos comportamentos do sujeito em sofrimento psíquico, decidem quando há necessidade de chamar os profissionais de assistência à urgência ou emergência (GOFFMAN, 1974).

No entanto, nem toda situação de crise psíquica irá circunscrever necessariamente uma realidade de urgência ou emergência em saúde mental. Tratar toda crise como uma urgência ou emergência é reflexo da intolerância e preconceito para com os sujeitos em sofrimento psíquico, bem como uma demonstração da incapacidade de compreender e aceitar o outro, cultivada em nosso cotidiano pela psiquiatria clássica e por outros reducionismos da pessoa à doença.

Os serviços de urgência ocupam um lugar tão estratégico quanto problemático na Rede de Atenção Psicossocial (RAPS), pois estão no último nível antes da internação psiquiátrica. Na maioria das vezes, esses serviços priorizam a sedação e o encaminhamento para a internação hospitalar quando se deparam com as manifestações de uma crise psíquica, fortalecendo a cadeia crise/emergência/ internamento como se fosse a principal, senão única, alternativa para conter a crise (DALMOLIM, 2006).

O Serviço de Atendimento Móvel de Urgência (Samu), como um serviço de atendimento pré-hospitalar de urgência, na maioria das vezes, incorpora a agilidade, funcionalidade e objetividade em sua política e prática assistencial. No que tange ao atendimento psiquiátrico, comumente, o serviço perpetua a execução de atitudes médico-repressivas, como contenções física e química, realizadas de forma errada e/ou em momentos em que não eram necessárias. Isso reforça as práticas manicomiais e entra em contradição com a Reforma Psiquiátrica brasileira (JARDIM, 2008). 
Essas denominadas práticas manicomiais desfavorecem a apreensão da subjetividade e reforçam a criação de dependência institucional ou profissional por parte dos sujeitos em sofrimento psíquico. Em contrapartida, a tomada de medidas que visem o vínculo, a reestruturação subjetiva do indivíduo e o respeito da sua singularidade, sem a necessidade de normatização, é capaz de fomentar autonomia e promover transformações significativas na qualidade de vida dos sujeitos acometidos por distúrbios mentais graves (WILLRICH et al., 2011)

É preciso que os serviços de urgência e emergência, tanto no seu componente móvel ou fixo, percebam o momento da crise psíquica como fundamental para propiciar acolhimento e compreensão da subjetividade manifestada durante a intensificação do sofrimento do usuário, buscando a interlocução entre profissionais e pacientes (ROSA; LUZIO; YASUI, 2003; DALMOLIM, 2006).

Portanto, esta pesquisa buscou respostas e suscitou questôes sobre o seguinte mote: as práticas dos profissionais de saúde do Samu do município de Natal, diante do atendimento a uma urgência psiquiátrica, articulam-se com a Reforma Psiquiátrica brasileira? Nesse sentido, objetivou-se discutir o atendimento prestado às urgências psiquiátricas pelos profissionais de saúde do Samu de Natal, Rio Grande do Norte (RN).

\section{Métodos}

Trata-se de uma pesquisa aplicada, de abordagem qualitativa, exploratória e do tipo estudo de caso, que utilizou a entrevista e a observação direta como instrumentos de coleta de dados. A entrevista semiestruturada foi adotada por permitir a presença ativa do pesquisador guiando a entrevista. Por sua vez, a observação direta demonstrou-se como um importante aliado na captação de informações contidas no cotidiano das práticas e que não se revelaram nos depoimentos dos profissionais. A aplicação dos instrumentos de coleta foi realizada mediante solicitação da assinatura do Termo de Consentimento Livre e Esclarecido (TCLE).

Os critérios de inclusão dos sujeitos da pesquisa foram: ser profissional de saúde lotado no Samu do município de Natal-RN e exercer atividades de assistência direta durante os atendimentos. Foram excluídos os profissionais que exerciam funções exclusivamente administrativas na instituição. 
A definição da amostra em pesquisas de abordagem qualitativa não obedece ao critério da representatividade numérica diante da população do estudo. Isso é desnecessário porque a preocupação maior não está nessa representatividade, mas na necessidade de a amostra espelhar dimensões sociais, culturais e particulares de um contexto em contínua construção. Nessa perspectiva, adotamos o método de definição amostral por saturação teórica de informações. A técnica consiste em interromper a coleta quando não há acréscimo significativo do conteúdo apreendido, ou seja, quando a continuidade da coleta de dados traz, majoritariamente, repetiçôes daquilo que já foi identificado em momentos anteriores (FONTANELLA; RICAS; TURATO, 2008).

Diante disso, a amostra do estudo foi composta por 24 sujeitos distribuídos entre as seguintes profissões: quatro médicos, seis enfermeiros e quatorze técnicos de enfermagem. Em relação ao gênero, a amostra contou com dezessete homens e sete mulheres. Trata-se de uma amostra por conveniência na qual os sujeitos foram abordados pessoalmente no serviço e convidados a participar das entrevistas.

As entrevistas foram gravadas individualmente, com duração média de 30 minutos e em ambientes fechados e reservados, o que facilitou a livre expressão da subjetividade de cada participante, bem como o sigilo e anonimato. Logo em seguida, os depoimentos e observaçôes de campo foram transcritas e apreciadas através da técnica da análise temática, que possibilitou a identificação da interface entre as falas dos sujeitos em suas categorias com as estruturas sócio-históricas inerentes ao problema da pesquisa (RODRIGUES; LEOPARDI, 1999). A técnica possibilitou a construção de quatro categorias de análise que se voltam para a assistência prestada pelos profissionais de saúde do Samu-Natal nos casos de urgência psiquiátrica.

Este estudo seguiu as diretrizes da Resolução no 466/13 do Conselho Nacional de Saúde que norteia a realização de pesquisas envolvendo seres humanos no Brasil e foi avaliado e aprovado pelo Comitê de Ética em Pesquisa da UFRN (CAAE nº 0190.0051.000-09).

\section{Resultados e discussão}

A análise deste estudo se volta para a assistência prestada pelos profissionais de saúde do Samu-Natal nos casos de urgência psiquiátrica. A partir dos depoimentos, foram construídas quatro categorias: a Polícia Militar e as ocorrências 
psiquiátricas; características do atendimento prestado pelo Samu em urgências

psiquiátricas; necessidade de capacitação profissional; e, responsabilidade do Samu com as urgências psiquiátricas.

Como o atendimento do Samu começa com o atendimento da ligação na sala de regulação médica, discutem-se alguns aspectos identificados durante as observações diretas da pesquisa nesse ambiente. Nesses momentos, é perceptível que o setor é muito estressante, principalmente para o médico regulador. Durante os plantões, existem muitas solicitações para atendimento que não circunscrevem urgências e emergências, foco de atuação do Samu.

Corroborando isso, percebeu-se que o número de ambulâncias disponíveis ao atendimento da população municipal é insuficiente em várias situações. Os chamados superam a capacidade operacional de atendimento do Samu-Natal, gerando longa fila de espera e demora no atendimento dos chamados não classificados em código vermelho, ou seja, prioritários. O desequilíbrio entre a demanda e a procura pelos serviços e as solicitaçoos indevidas, relacionadas, principalmente, à falta de informação da população, fazem com que os médicos reguladores tenham que vivenciar constantes ameaças e agressões verbais deferidas pelos usuários do serviço.

Em relação à saúde mental, atualmente, a RAPS do município possui serviços substitutivos, ambulatoriais e hospitalares, tanto para o cuidado das pessoas com sofrimento psíquico, como para o tratamento de dependência química em álcool e outras drogas, incluindo a atenção ao público infanto-juvenil e também o acompanhamento de familiares. Os serviços que constituem a RAPS de Natal-RN são, portanto: três Consultórios de Rua; dois Serviços Residenciais Terapêuticos; cinco Centros de Atenção Psicossocial (CAPS); cinco serviços ambulatoriais, sendo três em Policlínicas; serviços hospitalares como o Hospital Colônia João Machado; e serviços de urgência contando com a assistência do Samu.

Diante desse cenário, a assistência das ocorrências psiquiátricas, realizada pelos profissionais no local da ocorrência, será discutida a partir das categorias identificadas na análise e expostas a seguir.

\section{A Polícia Militar e as ocorrências psiquiátricas}

Segundo a Portaria no 2.048/GM, uma das funções do Samu durante o atendimento é reconhecer a necessidade de acionar outros atores no atendimento 
1298 às urgências psiquiátricas, quando vítimas agressivas promoverem situações de risco para si e para os outros, incluindo a segurança da equipe de Atendimento Pré-Hospitalar (APH) (BRASIL, 2003). Esse aspecto é evidenciado nas falas dos profissionais, que justificam a necessidade de acionar a Polícia Militar (PM) sob o argumento do risco de agressividade.

A gente tem que acionar a PM pra que eles possam, se o paciente estiver agressivo, conter o paciente de uma forma que ele não vá causar mal nenhum à nossa equipe (Entrevistado 14).

A gente precisa pedir apoio da polícia, pra prender, pra interceptar (Entrevistado 2).

A linguagem representada pelos termos "prender" e "interceptar" assemelha-se a um fenômeno de julgamento moral ou mesmo de criminalização do sujeito em crise psíquica, conforme era praticado durante o período da grande internação na Europa (FOUCAULT, 1972). Além disso, a visão estigmatizada do paciente psiquiátrico sob o viés do medo, da periculosidade e da agressividade alimenta as práticas coercitivas durante a intervenção em crise psíquica.

Nesse contexto, está presente a contenção mecânica repressiva e violenta, muitas vezes, executada pela polícia. Nas entrelinhas dessas ações estão as relações de poder que caracterizam a Psiquiatria clássica e sua autoridade de tomar o corpo como objeto de suas práticas (CAPONI, 2009). Portanto, tais práticas vão de encontro ao ideário da Reforma Psiquiátrica brasileira e prejudicam a assistência aos pacientes psiquiátricos no contexto do atendimento pré-hospitalar de urgência.

Não se pode continuar na defesa de que todo paciente psiquiátrico em crise é potencialmente agressivo, pois isso é reflexo do preconceito e da falta de preparo para as intervençôes em urgências psiquiátricas. $\mathrm{O}$ medo faz com que os profissionais solicitem a presença de um policial dentro da ambulância, mesmo depois do paciente contido, confirmando o motivo para tantas solicitaçôes pela polícia por parte do Samu-Natal.

A gente notando que ele ainda está agitado, inquieto, que às vezes ele pode até dar o surto de novo, a polícia vai na ambulância sentado com a gente (Entrevistado 7).

Por motivo de despreparo e medo. Tem que ser profissionais especializados porque eles sabem o jeito de abordar e como falar com o paciente que está com transtorno mental, abordando com ética, humanização e técnica (Entrevistado 21).

Concorda-se com a existência de situações nas quais pode haver a necessidade de intervenção de outros equipamentos sociais para preservar a integridade dos envolvidos nas circunstâncias de uma urgência psiquiátrica, inclusive da própria 
vítima. Porém, os profissionais do Samu-Natal precisam ser capazes de identificar as situações em que o risco esteja realmente presente nas urgências psiquiátricas, afastando-se das intervenções pautadas por julgamentos de risco preconceituosos e estigmatizados, alicerçados pelo ideário social da loucura.

Nesse sentido, o profissional deve dispensar o uso da força policial, direcionar seu olhar para as necessidades do paciente e utilizar o diálogo como prioridade de intervenção, ou seja, pautar-se no recurso teórico e científico pertinente ao profissional de saúde, sem negar o atendimento. Apesar disso, o próprio SamuNatal encontra necessidade contínua da participação da polícia durante as ocorrências psiquiátricas, acarretando prejuízos na relação entre os profissionais, como reconhecem.

O importante seria a nossa equipe conseguir chegar lá e poder lidar com o paciente psiquiátrico sem precisar da ajuda da PM (Entrevistado 14).

Um dos agravantes encontrados pelos profissionais na relação de dependência do Samu-Natal com a PM, no que concerne ao atendimento às urgências psiquiátricas, é o fator tempo. O protocolo de atendimento e os indicadores de qualidade do Samu estão norteados pelo tempo mínimo necessário para chegar à cena da ocorrência (BRASIL, 2003). Em contraposição, o fator tempo não é prioridade para a polícia quando se trata do auxílio prestado nas ocorrências psiquiátricas.

A gente chega na ocorrência, avalia que o paciente necessita de um apoio hostil, de um apoio da polícia e acaba perdendo 20 ou 30 minutos de espera (Entrevistado 20).

Porque a PM não chega e a equipe não vai realmente entrar em atrito com o paciente (Entrevistado 19).

Como deposto, além do fator tempo, encontra-se referência à necessidade de um "apoio hostil" nas urgências psiquiátricas. Essa fala retrata um antagonismo conceitual, por compreender que, se alguma prática é hostil, não pode ser considerada como apoio, pelo menos não para o paciente. Na verdade, através do discurso percebe-se a necessidade de auxílio para que polícia e profissionais possam exercer sua hostilidade sobre a pessoa em crise psíquica. Além disso, é ressaltada a preocupação de não entrar em atrito com o paciente durante a abordagem em crises psíquicas. Porém, se intervenção é sinônimo de "atrito", então, essa equipe precisa rever suas práticas, articulando-as com a integralidade e a equidade como princípios e diretrizes do SUS. 
Em contrapartida, a intervenção da polícia também é vista por alguns profissionais entrevistados como positiva para aprimorar o atendimento de urgência e diminuir o seu tempo, alegando-se o poder militar de intimidação e o medo que a maioria dos pacientes psiquiátricos tem da polícia.

Quem nos apoia, na realidade, é a Polícia Militar. De uma forma, muitas vezes, que amedronta o doente e esse doente acuado, ele se entrega pra gente, pra gente fazer o transporte (Entrevistado 1).

Ele sabe que a polícia chega pra bater e não pra conversar com ele, nem pra oferecer apoio (Entrevistado 10).

$\mathrm{Na}$ verdade, nessas situações, o sujeito em sofrimento psíquico, como qualquer ser humano humilhado e subjugado em sua condição, não se entrega: mortificase e aceita o transporte (GOFFMAN, 1974). Os trabalhadores de saúde - e portanto, do cuidado - que esperam o "doente ficar acuado" e "se entregar" não deveriam postar-se de maneira negligente e passiva.

Assim sendo, a questão em torno dessa discussão é que o paciente em crise psíquica só se sente acuado pelo medo da possível violência e do abuso da força que podem ser praticadas pelo policial. Trata-se de agressão deflagrada contra uma pessoa já fragilizada pelo seu sofrimento psíquico, com o consentimento dos profissionais de saúde, que deveriam acolher e cuidar.

O caráter violento decorrente do despreparo da polícia para as intervenções em urgências psiquiátricas, bem como o substrato da percepção do paciente psiquiátrico como contraventor ("descer o bastão") ou como animal ("amansam"), são identificados nos trechos.

A polícia não tem a noção do que é um paciente doente mental (...) e quando a polícia chega, eles amansam na mesma hora. A maioria dos policiais já vem pensando em descer o bastão, então por isso que os pacientes têm medo (Entrevistado 13).

A gente sabe que o paciente não é aquilo, ele está passando por um momento e a polícia não entende, age com violência, às vezes agride verbalmente o paciente sem necessidade e submete-o a coisas que não são necessárias (Entrevistado 17).

Percebe-se que no Samu-Natal, assim como em serviços de atenção à saúde no Brasil referidos em estudos, existem muitos profissionais em processo de transição que, embora conservem o discurso e as concepções do modelo da psiquiatria tradicional, também defendem as novas diretrizes baseadas na atenção psicossocial (MORAIS et al., 2009). Isso revela a mutação paradigmática na área da Saúde Mental, onde as certezas da psiquiatria clássica começam a perder 
espaço para os questionamentos da Reforma Psiquiátrica brasileira, saúde mental e atenção psicossocial.

Entretanto, para que esse processo se concretize, os profissionais de saúde não podem compartilhar com a polícia a tarefa de atemorizar e moralizar adultos (GOFFMAN, 1974). O estigma da agressividade do paciente psiquiátrico não deve continuar justificando o concílio médico-repressivo indiscriminado entre Samu e polícia durante o atendimento às crises psíquicas, pois tais posturas desvalorizam todo o contexto da Reforma Psiquiátrica brasileira em prol da desinstitucionalização (JARDIM, 2008).

É preciso, sim, avançar na compreensão da crise enquanto evento que demanda acolhimento, diálogo, aproximação entre os sujeitos envolvidos e respeito às necessidades subjetivas e particularidades de cada usuário dos serviços de saúde. Para tanto, se faz necessária articulação entre o Samu e a RAPS, na perspectiva de construir instrumentos, saberes e práticas para a consolidação efetiva de uma abordagem integral e humanizada. Quando se fala em uma abordagem pautada na integralidade, reflete-se sobre práticas baseadas na articulação entre clínica e Saúde Coletiva em todos os níveis de atenção do SUS, tanto nos serviços de atenção à saúde em geral, como nos setores específicos de saúde mental, com o mote central das necessidades do usuário. Essa integralidade só será alcançada através do intercâmbio de saberes/práticas e de alteração nas relações de poder estabelecidas, por meio da instituição de uma lógica do trabalho interdisciplinar (FIGUEIREDO; CAMPOS, 2008).

Contudo, a articulação do Samu-Natal com a RAPS do município não foi identificada nessa pesquisa, conforme se aponta durante a análise da próxima categoria.

\section{Características do atendimento prestado pelo Samu em urgências psiquiátricas}

A partir das fichas de atendimento disponíveis no sistema eletrônico de ocorrências do Samu-Natal, observa-se que entre os meses de janeiro a março de 2010 ocorreram 314 chamadas para urgências em saúde mental, das quais $74 \%$ foram finalizadas com o transporte para o Hospital Colônia João Machado, hospital psiquiátrico do município de Natal-RN. Esse número é confirmado pelas falas dos profissionais entrevistados. 
$\mathrm{Na}$ realidade, as nossas urgências psiquiátricas são muito mais transporte. Você vai lá, contém o doente e o transporta para hospital psiquiátrico (Entrevistado 1).

Surto, droga, alcoolismo, tudo leva para lá, a gente trabalha com o João Machado (Entrevistado 24).

Sobre esse aspecto, ressalta-se que o Samu não deve se limitar a um mero instrumento de transporte manicomial e sim agir de forma incisiva, contemplando as diretrizes da Reforma Psiquiátrica brasileira (JARDIM; DIMENSTEIN, 2008). De fato, as características do Samu, como um serviço móvel de atendimento, propiciam uma posição estratégica como articulador de serviços assistenciais. Isso porque, quando as ações em saúde mental são realizadas onde as pessoas convivem, como é o caso do atendimento pré-hospitalar, inverte-se o paradigma asilar, pois o sujeito é atendido inserido em seu conjunto de vínculos, de relações compartilhadas e com sua participação direta. Além disso, esse tipo de serviço garante a acessibilidade geográfica, que se traduz pela facilidade de ser atendido, bem como a acessibilidade política, que se operacionaliza pelo modo participativo de assistência na comunidade (HIRDES, 2009a).

Considera-se, também, que, ao atender as urgências psiquiátricas, o Samu pode articular suas intervençóes juntamente com qualquer serviço da rede de assistência em saúde. Dessa forma, não faz sentido continuar pensando no hospital psiquiátrico como destino prioritário para os pacientes em crise psíquica. No entanto, destaca-se a fala a seguir:

$\mathrm{O}$ atendimento ao paciente psiquiátrico tem direcionalidade ao hospital, muitas vezes até usando a força. Então, eu não acredito em nenhuma mudança nesse perfil da saúde mental em relação ao serviço pré-hospitalar (Entrevistado 16).

O discurso anterior destaca a ideia fragmentada de que o Samu não abrange a articulação com outros serviços da rede assistencial em saúde mental e não tem espaço para as mudanças no perfil do atendimento psiquiátrico no setor de urgência. Portanto, tem-se uma defesa direta do modelo manicomial de contenção mecânica, transporte e internação como estratégia de intervenção nas urgências psiquiátricas.

O encaminhamento dos sujeitos em crise psíquica para o hospital psiquiátrico, sem levar em consideração as possibilidades assistenciais oferecidas pelos serviços substitutivos em saúde mental, criados a partir da Reforma Psiquiátrica brasileira, nos remete às características do atendimento prestado durante os primórdios da 
Psiquiatria clássica. Essa desarticulação entre Samu-Natal e a rede de serviços substitutivos em saúde mental é destacada no discurso a seguir:

Nós não temos muito contato com o CAPS (Centro de Atenção Psicossocial)! A gente pega o paciente ou na residência ou em via pública e transfere para o João Machado (Entrevistado 24).

A necessidade de articulação entre Samu e os componentes especializados da rede de saúde mental aponta para duas modalidades: a articulação interna dos serviços, que não pode se voltar exclusivamente para aspectos burocráticos ou procedimentais e precisa avançar na centralidade assumida pela subjetividade dos usuários em crise; e a articulação externa, na qual o serviço demonstra capacidade de absorver saberes e recursos externos às suas práticas (HIRDES, 2009a). Nesse sentido, a falta de integração entre o Samu-Natal e a RAPS e a postura fechada para as conquistas e avanços da Reforma Psiquiátrica brasileira contribuem para que o serviço se configure como uma alternativa de promover a internação. Portanto, concorda-se que "os muros a serem demolidos são aqueles que impedem a utilização de outros saberes e recursos" (HIRDES, 2009a, p. 302).

As instituiçōes formadoras de profissionais de saúde também são apontadas por autores e por alguns profissionais como corresponsáveis na busca por melhorias na qualidade da assistência prestada ao sujeito em crise psíquica. Estas podem contribuir com a articulação de serviços e na operacionalização de uma rede efetiva de saúde mental, cujo centro de intervençôes deixe de ser o hospital psiquiátrico e passe a ser o indivíduo acometido pelo transtorno mental. Concorda-se que essa articulação pode contribuir nesse contexto; porém, defende-se que não basta retirar o Hospital Colônia João Machado da prioridade de destino dado pelo Samu-Natal aos pacientes em crise psíquica: torna-se primordial fortalecer outros serviços de saúde mental como possibilidade de referência. É preciso transformar toda a lógica do atendimento, que tem centrado suas práticas na contenção mecânica e na sedação durante as urgências psiquiátricas, conforme se identifica a seguir.

Precisa de um atendimento e de uma medicação que possa sedá-lo para que a gente possa encaminhá-lo ao hospital psiquiátrico (Entrevistado 12).

A gente tem que fazer contenção mecânica e levar o paciente o quanto antes para o hospital (Entrevistado 9). 
Uma questão peculiar à discussão da assistência repetitiva, burocrática e não singularizada prestada aos pacientes psiquiátricos é a da contenção química. A descoberta dos medicamentos psicotrópicos possibilitou um avanço significativo para a assistência em saúde mental, sobretudo, durante o processo de desinstitucionalização, visto que as drogas compõem as intervenções contidas nos planos terapêuticos dos usuários dos serviços substitutivos.

Ressalva-se, porém, que o uso da psicofarmacologia não é a única alternativa à disposição dos profissionais para contemplar as necessidades do sujeito durante seu tratamento ou abordagem. O medicamento não pode ser visto como uma forma mágica de sanar os comportamentos que possam estar causando incômodo, constrangimento ou medo a partir da visão estigmatizada da doença mental. $\mathrm{O}$ uso da sedação deve ser feito com critério e indicação clínica condizente, como quando o sujeito põe em risco concreto a sua integridade ou a de outras pessoas.

Entretanto, o uso de medicamentos psicotrópicos no Samu fica prejudicado mesmo quando existe indicação para sua prática, já que a maioria das ocorrências psiquiátricas é atendida pelas ambulâncias de suporte básico de vida, que não dispõem dessas drogas para intervenção. Isso significa que, em situação extrema, na qual o paciente manifesta comportamentos de risco para sua vida ou integridade física e que outras estratégias de aproximação tenham falhado, o profissional desse tipo de ambulância só dispõe da contenção mecânica para intervir, remetendo o atendimento por meio de atitudes repressivas e violentas que aumentam o desespero e angústia dos sujeitos em sofrimento psíquico.

Toda abordagem é feita em cima de restrição e contenção, a gente não trabalha nas Unidades de Suporte Básico com contenção química (Entrevistado 1).

Nesse sentido, observa-se que as ambulâncias de suporte básico de vida priorizam a contenção mecânica, as de suporte avançado de vida focalizam a contenção química, e ambas, por meio das práticas dos profissionais, buscam a internação hospitalar como estratégia de tratamento prioritário para os sujeitos em crise psíquica.

Diante das limitações das ambulâncias de suporte básico de vida para o atendimento das urgências psiquiátricas, os profissionais do Samu-Natal acrescentam:

Deveria ter um carro apropriado, com menos coisas dentro e mais seguro (Entrevistado 13). 
O Samu tinha que ter uma ambulância especializada, uma ambulância que seja forra-

da e pessoas preparadas para a contenção física com camisa de força (Entrevistado 19).

Deveria ter um serviço do Samu específico só para psiquiatria, onde a ambulância pudesse isolar o paciente impossibilitando o contato, onde ele pudesse ficar confortável e sem agredir ninguém (Entrevistado 11).

A fala dos profissionais sobre as características dessa suposta ambulância, específica para os atendimentos psiquiátricos, nos remete à figura literal de um camburão acolchoado, destinado ao transporte e internação dos sujeitos em crise psíquica. Não faz sentido mudar as ambulâncias sem pensar na transformação da atitude do profissional durante o atendimento, visto que um ambiente humanizado também se constitui pela intervenção de um profissional acolhedor.

Destarte, a formulação de estratégias de educação continuada realizada por profissionais capacitados na área de Saúde Mental poderia contribuir no sentido de oferecer suporte para mudanças no cenário supracitado, melhorando a escuta, ampliando os saberes e fazeres da clínica cotidiana, incorporando noções de acolhimento do sofrimento psíquico e de interação com a subjetividade do usuário.

\section{Necessidade de capacitação profissional}

$\mathrm{O}$ combate efetivo à realização das práticas manicomiais que violentam a subjetividade da pessoa com transtorno mental implica a reinvenção na sociedade em que vivemos. Durante esse processo, é preciso ter em mente que a transformação da realidade social não poderá acontecer por meio de técnicas ou fórmulas, mas através da revelação e combate dos pontos de sustentação que a própria sociedade impõe aos seus membros (HIRDES, 2009b).

Visualiza-se um caminho para esse propósito através da educação permanente nos serviços e pelas transformações dos currículos tradicionais na formação em saúde, sobretudo em Saúde Mental, que, predominantemente, continua a ser organizada de forma disciplinar, voltada para a especialização, fragmentação, medicalização e reforço do paradigma psiquiátrico hospitalocêntrico (YASUI; ROSA, 2008). Observa-se a seguir que a capacitação é apreendida sob o viés da fragmentação e da medicação.

Uma aula, um minicurso com um colega psiquiatra já seria ideal pra poder nos dar um apoio científico (Entrevistado 19).

Treinamento específico, tanto para o médico, no sentido da utilização de medicamentos e da utilização de técnicas de contenção que não agridam o paciente (Entrevistado 8). 
As falas não apontam para a necessidade de apreender o cuidado ao sujeito em crise psíquica por meio da valorização do diálogo, da percepção da singularidade no seu sofrimento e da adoção de estratégias terapêuticas condizentes com cada caso. Pelo contrário, os profissionais percebem a capacitação como estratégia para legitimar "cientificamente" uma prática atrelada aos primórdios da psiquiatria, quando o foco era a contenção e o isolamento.

Apesar de o Samu-Natal dispor de um auditório e do Núcleo de Educação Permanente (NEP), com profissionais dedicados à realização de educação continuada no serviço, segundo os profissionais entrevistados não há foco nas urgências psiquiátricas durante atividades desenvolvidas.

Nós não temos nenhum tipo de treinamento para esse tipo de ocorrência, nem nós, nem os técnicos de enfermagem, nem os condutores, ninguém (Entrevistado 8).

$\mathrm{Na}$ verdade os nossos treinamentos focalizam mais a urgência e emergência clínica, da parada, do acidente, do politraumatizado, do que outros atendimentos (Entrevistado 16).

A implementação efetiva de atividades de educação permanente em saúde, voltadas à equipe multiprofissional e centrada em saúde mental, pode contribuir sobremaneira para a redefinição do fazer na atenção às urgências psiquiátricas por parte do Samu-Natal. Isso porque nesse processo, ocorre a incorporação gradativa de tecnologias leves, relativas ao acolhimento, diálogo e responsabilização, bem como de tecnologias leves/duras, que contribuem para a construção de saberes e práticas bem estruturadas (TANAKA; RIBEIRO, 2009). Alguns profissionais percebem essa indigência:

Deveria ter mais treinamento para a gente ver esse paciente de forma humanizada, ter que conversar com ele, com a família e buscar resgatar o vínculo profissional de saúde com esse paciente necessitando do nosso atendimento (Entrevistado 7).

Tratar uma urgência psiquiátrica vai muito além do que você dar a medicação e sedar o paciente. Envolve muito mais, envolve o ambiente do paciente, a família do paciente e o paciente em si. Então, eu não me sinto preparado, não tive esse tipo de treinamento (Entrevistado 8).

Além da realização de estratégias de educação permanente em saúde, é preciso voltar o olhar para o modo de operacionalizar tais açóes, contribuindo para que o serviço redefina suas práticas e flexibilize seu poder de intervenção. Em particular, as capacitações do NEP do Samu-Natal podem estar abertas para essa necessidade e não centrar as atividades desenvolvidas na transmissão de conhecimento e técnicas em uma perspectiva tradicionalista do processo educacional. 
O método é crucial, mas a aproximação entre teoria e prática durante a escolha e abordagem dos conteúdos é um elemento importante para o sucesso da educação permanente nos serviços. Nesse contexto, os estudos de casos hipotéticos ou reais, resgatados das fichas de atendimentos do Samu, podem mostrar-se uma boa estratégia, visto que a partir da problematização e reflexão sobre seu cotidiano os profissionais sentem-se mais capacitados em atender casos de saúde mental e ganham maior autonomia (DELFINI, 2009).

Sem o suporte teórico fornecido por estratégias de educação permanente nos serviços, realizadas a partir da crítica e reflexão no processo ensino/aprendizagem, a tendência das instituições que trabalham no contexto da saúde mental seria a utilização do aparato manicomial durante a assistência prestada. Nesse sentido, mesmo no espaço da formação em saúde, é indispensável (re)direcionar os currículos e as práticas pedagógicas para a construção de competências voltadas à atenção psicossocial.

\section{Responsabilidade do Samu com as urgências psiquiátricas}

Nos serviços de atendimento de urgência, tanto no seu componente fixo como no móvel, impera o modelo da clínica tradicional, através do qual a objetividade, o controle do tempo e a prática de ações protocoladas são os fundamentos $\mathrm{da}$ assistência prestada. Nesse âmbito, o atendimento às urgências psiquiátricas compreende tudo aquilo de que a emergência clínica procura se eximir. Esse tipo de assistência remete a outra ordem de complexidade, que precisa do pensamento criativo e questiona a posição dominante do médico (JARDIM, 2008).

Os conflitos gerados pela percepção dessas peculiaridades e, consequentemente, as diferenças no caráter do atendimento fazem com que os profissionais compreendam que as urgências psiquiátricas não deveriam ser responsabilidade do Samu.

Na verdade, eu sempre fui contra o Samu atender esse tipo de chamado. Eu acho que deveria existir um setor no hospital psiquiátrico aqui de Natal responsável por isso (Entrevistado 2).

Deveria haver um serviço só voltado pra esse tipo de ocorrência (Entrevistado 8).

O Samu não deveria fazer esse serviço, acho que deveria ser a polícia militar (Entrevistado 13). 
$\mathrm{Na}$ defesa pela desresponsabilização do Samu com a atenção às crises psíquicas, os profissionais apontaram o hospital psiquiátrico e a polícia militar como os responsáveis por atender esse tipo de demanda. Entretanto, nenhuma das instituições apontadas pode assumir a referência para realizar esse tipo de atendimento, pois a Reforma Psiquiátrica brasileira restringe, significativamente, os poderes das instituições psiquiátricas hospitalares e aponta em suas discussões que a doença mental não deve ser criminalizada e nem tratada como caso policial. Desse modo, essas sugestões são uma afronta às políticas de saúde mental no Brasil.

$\mathrm{Na}$ verdade, trata-se de uma tentativa de negar algo que, em sua complexidade, não se encaixa nos rígidos protocolos de atendimento do Samu e que, portanto, se torna um empecilho por trazer grandes dificuldades para os profissionais de saúde formados e capacitados para um tipo de intervenção pautada na lógica de causa e efeito. Esse contexto faz com que alguns profissionais resistam a prestar atendimento às urgências psiquiátricas.

Às vezes a gente tem solicitado o apoio das motolantes no sentido de apoiar na urgência psiquiátrica, mas às vezes o condutor dessa moto, ele quase se recusa, 'eu não vou me agarrar com ninguém!' (Entrevistado 1).

Compreende-se que os profissionais entrevistados tornam-se mais vítimas do que vilóes da realidade descrita. Eles foram formados e treinados para trabalhar em uma perspectiva, e uma situação, em particular, coloca em xeque todo suporte teórico norteador de sua prática, sem que recebam o devido apoio.

Esse profissional precisa ser bem assistido também, porque o desgaste é grande. Tem que ter interesse pelos profissionais, ninguém valoriza, chama de doido também! (Entrevistado 21).

Reitera-se a relevância de efetivação da educação permanente em Saúde Mental para que esses profissionais possam compreender a complexidade da situação de crise psíquica e suas possibilidades de intervenção. Assim, é preciso direcionar as ações desde o princípio para o rompimento com o paradigma da clínica de emergência.

Caso não haja ações nesse sentido, o atendimento às urgências psiquiátricas vai continuar a ser visto como um aborrecimento para o serviço do Samu. Essa configuração pode contribuir para que a assistência de pessoas em crise psíquica seja negligenciada pelo Samu-Natal, fato identificado a seguir:

Muitas vezes o doente psiquiátrico corre muito mais risco, porque a nossa rotina é deixar em segundo plano a urgência psiquiátrica (Entrevistado 1). 
Infelizmente, não tem como priorizar esse tipo de atendimento. Então, às vezes fi-

cam fichas aguardando aí uma hora, uma hora e meia, às vezes até mais do que isso (Entrevistado 2).

A maioria dos pacientes em urgência psiquiátrica, quando você demora muito a chegar lá, acaba não tendo grande problema e nenhuma repercussão. Mas, já aconteceu de a gente demorar demais e ter sido problemática essa demora (Entrevistado 19).

Apesar da falta de "repercussão" citada na fala anterior, a demora no atendimento para os casos de urgência psiquiátrica pode implicar riscos sérios para o paciente e sua família. Embora os avanços teóricos promovidos pelas discussões da Reforma Psiquiátrica brasileira sejam incorporados nas políticas de Saúde Mental vigentes no Brasil, não se observa no Samu-Natal um avanço em suas práticas, no que se refere à assistência em crise psíquica.

A transformação dessa realidade passa também pelo interesse dos gestores municipais, estaduais e federais do SUS, que precisam se aproximar das realidades locais, inteirar-se sobre seus problemas e agir de forma resolutiva e integrada, no sentido de buscar soluções juntamente com os serviços. Não nos referimos, portanto, a ações ou programas pontuais e verticalizados, mas a um trabalho continuado de suporte e instrumentalização dos profissionais e serviços para o enfrentamento das divergências encontradas na complexidade do atendimento às urgências psiquiátricas.

Como aponta a literatura, "aquilo que outrora foi fortaleza visível da ordem tornou-se castelo de nossa consciência” (FOUCAULT, 1972). E é sobre esse "castelo da consciência" que precisamos direcionar nossas forças no sentido de transformar o modo como o transtorno psiquiátrico tem sido assistido, não só no Samu-Natal, mas em toda a rede pública de saúde.

\section{Consideraçōes finais}

A transformação da clínica e da forma de perceber e de atuar durante as crises psíquicas, em especial, no espaço de atenção do Samu, é de fundamental relevância para a consolidação da Reforma Psiquiátrica brasileira. Porém, essa transformação não se garante sem esforços coletivos, visto que sua construção tem fortes raízes históricas atreladas à Psiquiatria clássica e ao seu modelo para intervenção em crises psíquicas.

Em síntese, a necessidade apresentada ao longo da discussão é de que a crise psíquica seja compreendida como uma manifestação individual, mas que 
se apresenta e se desenvolve no âmbito coletivo, com todas as incoerências e antagonismos decorrentes da sua construção social e histórica. Assim, a assistência prestada nesses casos precisa manter os laços sociais, ambientais e afetivos dos sujeitos, evitando medidas violentas, de cunho repressor ou excludente, que comprometam a criação de novas e futuras relações por parte da pessoa em sofrimento mental.

Conforme exposto, a realidade da assistência do Samu aos casos de crise psíquica compõe um contexto complexo e multifacetado, permeado por elementos sociais e históricos intrínsecos à discussão sobre loucura e cuidados em saúde. Mas, ao mesmo tempo, esses aspectos são um estímulo para a produção de conhecimento científico que venha a contribuir para a consolidação de uma intervenção em urgências psiquiátricas humanizadas e articuladas com a Reforma Psiquiátrica brasileira, garantindo reinserção social e o resgate da cidadania para os sujeitos em sofrimento psíquico.

Destarte, contribui-se para outros ecos de saberes e práticas aplicados às urgências psiquiátricas, onde possam e devam ter chegado os conceitos, avanços e conquistas da Reforma Psiquiátrica brasileira. Com mais de vinte anos de luta antimanicomial, é preciso centrar esforços para que os manicômios não tenham apenas mudado de endereço, ainda que sejam unidades móveis de urgência. ${ }^{1}$

\section{Referências}

BRASIL. Ministério da Saúde. Política Nacional de Atenção às Urgências. Brasília: Ministério da Saúde, 2003. 228p (Série E - Legislação de Saúde).

CAPONI, S. Michel Foucault e a persistência do poder psiquiátrico. Ciênc. Saúde Coletiva, Rio de Janeiro, v. 14, n. 1, p. 95-103, jan./fev. 2009.

DALMOLIM, B. M. Esperança equilibrista: cartografias de sujeitos em sofrimento psíquico. Rio de Janeiro: Fiocruz, 2006. 214p.

DELFINI, P. S. de S. Parceria entre CAPS e PSF: o desafio da construção de um novo saber. Ciênc. Saúde Coletiva, Rio de Janeiro, v. 14, supl. 1, p. 1483-1492, set./out. 2009.

FIGUEIREDO, M. D.; CAMPOS, R. O.; Saúde Mental e Atenção Básica à Saúde: o apoio matricial na construção de uma rede multicêntrica. Saúde em Debate, Rio de Janeiro, v. 32, n. 78/79/80, p. 143-149, jan./dez. 2008.

FONTANELLA, B. J. B.; RICAS, J.; TURATO, E. R. Amostragem por saturação em pesquisas qualitativas em saúde: contribuições teóricas. Cad. Saúde Pública, Rio de Janeiro, v. 24, n. 1, p. 17-27, jan. 2008. 
FOUCAULT, M. História da loucura. 3a ed. São Paulo: Perspectiva, 1972. 551p.

GOFFMAN, E. Manicômios, Prisões e Conventos. São Paulo: Perspectiva, 1974. 314p.

HIRDES, A. A reforma psiquiátrica no Brasil: uma (re)visão. Ciênc. Saúde Coletiva, Rio de Janeiro, v. 14, n. 1, p. 297-395, jan./fev. 2009a.

. Autonomia e cidadania na reabilitação psicossocial: uma reflexão. Ciênc. Saúde Coletiva, Rio de Janeiro, v. 14, n. 1, p. 165-171, jan./fev. 2009 b.

JARDIM, K. F. S. B. O Serviço de Atendimento Móvel de Urgência (Samu) no contexto da reforma psiquiátrica: em análise a experiência de Aracaju/SE. 2008. 165f. Dissertação (Mestrado em Psicologia) - Centro de Ciências Humanas, Letras e Artes, Universidade Federal do Rio Grande do Norte, 2008.

JARDIM, K.; DIMENSTEIN, M. A crise na rede do Samu no contexto da Reforma Psiquiátrica. Saúde em Debate, Rio de Janeiro, v. 32, n. 78/79/80, p. 150-160, jan./dez. 2008. MORAIS, M. L. S. et al. Um estudo avaliativo das ações de saúde mental no estado de São Paulo. Saúde em Debate, Rio de Janeiro, v. 33, n. 81, p. 112-128, jan./abr. 2009.

RODRIGUES, M. S. P.; LEOPARDI, M. T. O método de análise de conteúdo: uma versão para enfermeiros. Fortaleza: Fundação Cearense de Pesquisa e Cultura, 1999.

ROSA, A. C.; LUZIO, C. A.; YASUI, S. Atenção psicossocial: rumo a um novo paradigma na saúde mental coletiva. In: BASAGLIA F. et al. (Orgs.). Arquivos de Saúde Mental e Atenção Psicossocial. Rio de janeiro: Nau, 2003. p. 13-44.

TANAKA, O. Y.; RIBEIRO, E. L. Ações de saúde mental na atenção básica: caminho para ampliação da integralidade da atenção. Ciênc. Saúde Coletiva, Rio de Janeiro, v. 14, n. 2, p. 477-486, mar./abr. 2009.

YASUI, S.; ROSA, A. C. A estratégia de Atenção Psicossocial: desafio na prática dos novos dispositivos de saúde mental. Saúde em Debate, Rio de Janeiro, v. 32, n. 78/79/80, p. 27-37, jan./dez. 2008.

WILLRICH, J. Q. et al. Periculosidade versus cidadania: os sentidos da atenção à crise nas práticas discursivas dos profissionais de um Centro de Atenção Psicossocial. Physis: Revista de Saúde Coletiva, Rio de Janeiro, v. 21, n. 1, p. 47-64, 2011.

\section{Nota}

${ }^{1}$ A. A. C. de Brito, D. Bonfada e J. Guimarães participaram da concepção, análise e interpretação dos dados, redação do artigo, revisão crítica relevante e aprovação final da versão a ser publicada. 


\section{Where the reform has not yet arrived: echoes of psychiatric emergency care}

Under the Brazilian psychiatric reform, assistance to psychic crisis represents a challenge for health policy, especially for emergency services. This article aims to discuss the care provided to psychiatric crises by health professionals of the Mobile Emergency Service (Samu). The research is the result of a master's thesis in Nursing, held in Natal, and used the semi-structured interviews and direct observation as a means of gathering information. Data were submitted to thematic analysis technique applied in qualitative studies. With this framework, there were four categories of analysis: the military police and psychiatric events; service features provided by Samu in psychiatric emergency; need for vocational training; and responsibility of Samu with psychiatric emergencies. The discussion shows that elements associated with the asylum practice, as the use of coercive force, mainly performed with the help of military police, still support the ideas and care of the professionals interviewed. However, the care provided in these cases need to maintain social ties, environmental and emotional subjects, avoiding violent measures of repressive or exclusionary nature. Therefore, the research raised reflection on issues relevant to the process of implementation of the Brazilian Psychiatric Reform within the emergency pre-hospital care.

> Key words: mental health; emergencies; crisis intervention. 